\title{
A Herpes zoster ophthalmicus case with partial nerve paralysis of the oculomotor
}

\author{
Adem Gül ${ }^{a^{*}}$, Serek Tekin ${ }^{\mathrm{b}}$, Erbil Seven ${ }^{\mathrm{c}}$,Tekin Yaşar ${ }^{\mathrm{c}}$ \\ ${ }^{a}$ Department of Ophthalmology, Faculty of Medicine, Ondokuz Mayls University, Samsun, Turkey \\ ${ }^{b}$ Urartu Lazer Eye Center, Van, Turkey \\ ${ }^{c}$ Department of Ophthalmology, Faculty of Medicine, Yüzüncü Yıl University, Van, Turkey
}

\section{ARTICLE INFO}

\section{Article History}

Received $\quad 09 / 05 / 2013$

Accepted $\quad 07 / 06 / 2013$

\section{* Correspondence to:}

Adem Gül

Department of Ophthalmology,

Faculty of Medicine,

Ondokuz Mayıs University,

Samsun, Turkey

e-mail: karsadem@yahoo.com

\section{ABSTRACT}

A 48 years old Caucasian male patient admitted to our clinic with left side blepharoptosis and left periorbital itching complaints. In physical examination, patient's left upper eyelid was totally ptotic and there was ulcerated periorbital skin lesions in the same side as well. There was a restriction with upward gaze in the left eye. Best corrected visual acuity was 20/100. There was fine keratic precipitates on the central and inferior area of the left endothelium and 3+ reaction in the anterior chamber. Patient was accepted with a diagnosis of herpes zoster ophthalmicus. Treatment was started in our department. Inflammation in the anterior chamber was completely resolved in the second week of treatment and visual acuity was 20/20 in left eye. In the fourth month of patient's visit, blepharoptosis was resolved but limitation of the upward gaze was not resolved in the examination. According to our knowledge, this case may be the first herpetic involvement of superior divison of the oculomotor nerve in the aspect of clinical signs and may add contribution to the literature.

J. Exp.Clin. Med., 2013; 30: 255-256

\section{Keywords:}

Herpes zoster

Oculomotor nerve

Oculomotor paralysis

Ptosis

\section{Introduction}

While superior part of oculomotor nerve innervates the levator palpebra and superior rectus muscles, the inferior part innervates the medial rectus, inferior rectus and superior oblique muscles (Yanoff and Duker, 2008).

Ophthalmoplegia can be seen with Herpes zoster ophthalmicus cases. Affected nerves are oculomotor, trochlear and abducens nerves (Chern and Margolis, 1998).

In this article, we aimed to report a rare case of Herpes zoster ophthalmicus with the involvement only superior division of the oculomotor nerve.

\section{Case Report}

A Caucasian male 48 years old admitted to our clinic with left ptosis and left periorbital itching complaints.

In physical examination, patient's left upper eyelid was totally ptotic and there was ulcerated periorbital skin lesions in the same side as well (Fig. 1). When the eyes move, the right eye were in normal ranges, there was a restriction with upward gaze in the left eye (Fig. 2). Direct and indirect light reflexes were present.

Best corrected visual acuities were 20/20 in the right eye and 20/100 in the left eye. There weren't any pathologies in anterior and posterior segment of the right eye. There was fine keratic precipitates on the central and inferior area of the left endothelium and 3+ reaction in the anterior chamber. Left fundus examination was normal. Intraocular pressures were 15 and $17 \mathrm{mmHg}$ in the right and left eyes, respectively. Patient was accepted as Herpes zoster ophthalmicus in our department and treatment was started as topical prednisolone six times, topical acyclovir ointment 5 times, topical cycloplegic three times and systemic acyclovir $800 \mathrm{mg} 5$ times in a day.

Inflammation in the anterior chamber was completely resolved in the second week of treatment and visual acuity was 20/20 in left eye. Cycloplegic was stopped and topical steroid 
was maintained as twice for a week. Topical and systemic acyclovir treatment were stopped in first month visit. In the fourth month visit, ptosis was resolved but limitation of the upward gaze was not resolved in the examination.

\section{Discussion}

Ptosis related to oculomotor nerve involvement is a rare condition in the literature (Schoenlaub et al., 1997; Im et al., 2007). In our case, we thought that levator palpebra and superior rectus muscles were involved, so we concluded that superior division of the oculomotor nerve may be effected. In this context, we reviewed the literature about Herpes zoster ophthalmicus and ocular motor nerve involvement.

Nigam et al. (1991) reported 22 Herpes zoster ophthalmicus cases. In this study eyelid edema was stated as the etiology of ptosis. They also reported iritis and iridocyclitis in $45 \%$ of patients. In our case there was no lid edema. The cause of ptosis was third nerve palsy.

In another study, 58 years old male patient with Herpes zoster ophthalmicus and complete ophthalmoplegia was reported (Fujiwara et al., 1990). In that case, eye movements was completely resolved in 5 months. In our patient, uveitis and ptosis was resolved within four months but upward gaze palsy was not resolved in the seven months visit.

Another ocular motor involvement with Herpes zoster was in the sixth nerve in a 76 years old female patient was reported (Iwao et al., 2006). Schoenlaub et al. (1997) reported two Herpes zoster cases with complete ptosis. Ptosis was developed within sixth and seven days when his patients were under Herpes zoster treatment.

Shin et al. (2005) and Im et al. (2007) also reported 70 years and 69 years old herpes zoster ophthalmicus patients with complete ophthalmoplegia, respectively.

After elimination of systemic disorders which lead to ptosis, involvement of occulomotor nerve should be considered in herpetic keratitis if patient have simultaneously started ptosis. Since biopsy of the nerve or different way of definite diagnosis couldn't apply to our patient, we concluded the diagnosis of oculomotor herpes involvement with simultaneously starting symptoms and resolving ptosis complaints within four month. We don't know why inferior division was not involved. There was a technical restriction in this study that we couldn't take images about uveitis in slit lamp microscope due to lack of anterior segment photography.
This case is one of rare cases presenting with herpetic keratitis, uveitis and the oculomotor nerve involvement. Extraocular muscle involvement is not a rare condition in herpes zoster ophthalmicus but this case is a very rare case in terms of herpetic involvement of superior divison of the oculomotor nerve in the aspect of clinical signs and may add contribution to the literature.

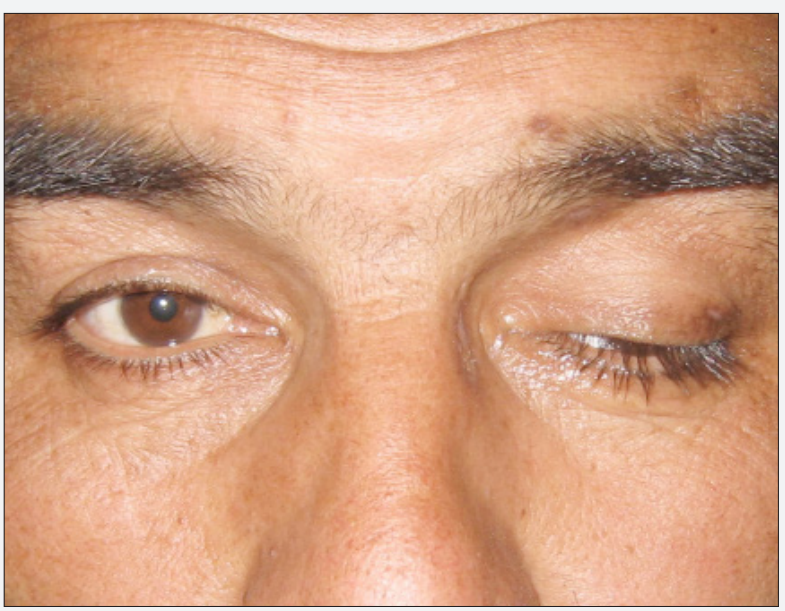

Fig. 1. Left sided ptosis

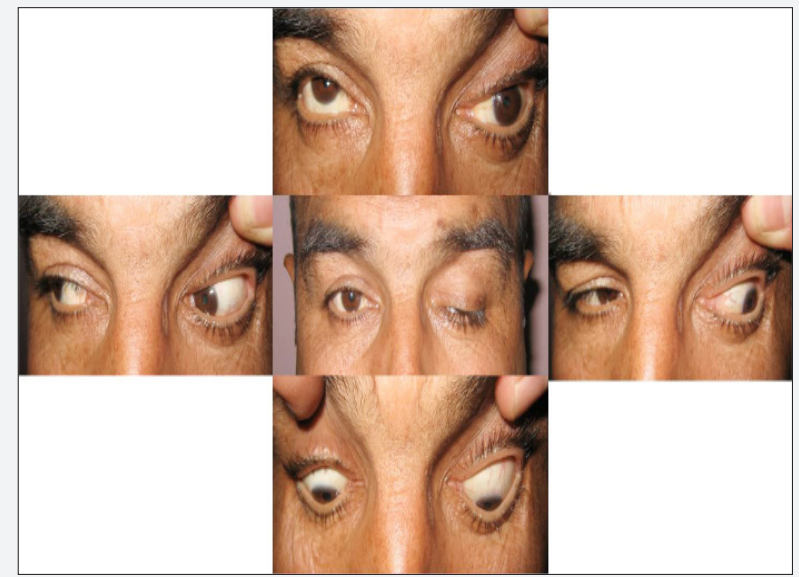

Fig. 2. Left upper gaze restriction

\section{REFERENCES}

Chern, K. C., Margolis, T.P., 1998. Varicella zoster virus ocular disease. Int. Ophthalmol Clin. 38, 149-160.

Fujiwara, M., Odashiro, M., Mizoguchi, H., Hayashi, I., Kawamura, J., Hashimoto, T., Tamura, K. A., 1990. Case of herpes zoster ophthalmicus with complete ophthalmoplegia. Masui. 39, 248-252.

Im, M., Kim, B.J., Seo Y.J., Park J.K., Lee J.H., 2007. Complete ophthalmoplegia after herpes zoster. Clin. Exp. Dermatol. 32, 162-164.

Iwao, K, Kobayashi, H., Okinami S., 2006. Case of herpes zoster ophthalmicus with abducent palsy: The cause and magnetic resonance imaging findings. Nippon Ganka Gakkai Zasshi. 110, 193-198.

Nigam, P., Kumar, A., Kapoor, K.K., Sarkari, N.B., Gupta, A.K., Lal B.B., Mukhija R.D., 1991. Clinical profile of herpes zoster ophthalmicus. J. Indian Med. Assoc. 89, 117-119.

Schoenlaub, P., Grange, F., Nasica, X., Guillaume, J.C., 1997. Oculomotor nerve paralysis with complete ptosis in herpes zoster ophthalmicus: 2 cases. Ann. Dermatol. Venereol. 124, 401-403.

Shin, H.M., Lew, H., Yun, Y.S., 2005. A case of complete ophthalmoplegia in herpes zoster ophthalmicus. Korean J. Ophthalmol. 19, $302-304$. Yanoff, M., Duker, J. S., 2008. Ophthalmology $3^{\text {rd }}$ edition. Edinburgh: Mosby. pp. 1303. 